Research Article

\title{
Comparison of new drug approval by regulatory agencies of US, EU and India
}

\author{
Bhaven C. Kataria*, Pavan J. Panchal, Ashwin K. Panchasara, \\ Ashna S. Pandya, Mitul R. Parmar
}

Department of Pharmacology, GMERS Medical College, Sola, Ahmedabad-380060, Gujarat, India

Received: 4 January 2016

Revised: 18 January 2016

Accepted: 25 January 2016

*Correspondence to:

Dr. Bhaven C. Kataria,

Email: drbkataria@gmail.com

Copyright: (C) the author(s), publisher and licensee Medip Academy. This is an openaccess article distributed under the terms of the Creative Commons Attribution NonCommercial License, which permits unrestricted noncommercial use, distribution, and reproduction in any medium, provided the original work is properly cited.

\begin{abstract}
Background: As per World Trade Organisation (WTO), from the year 2005, India granted product patent recognition to all new chemical entities (NCEs). This may affect the new drug approvals in India. The purpose of this study was to compare the new drug approvals in India with the United States (US) and the European Union (EU) regions.

Methods: We obtained information about regulatory approval of new drugs in the US, EU, or India of last 5 years (from 2011 through 2015) from the publicly accessible databases of three regulatory agencies. For the drug products identified, the drugs were classified into fourteen main Anatomical Therapeutic Chemical (ATC) groups, review classification and approval date.

Results: There were 509 new drugs approved from 2011 through 2015 by one or more of the three regulatory agencies. Total 182 new drugs were approved in US during the period of 2011 to 2015, with an average of 36.4 new drugs approved per year. For the same period a total of 257 new drugs were approved in the EU, with an average of 51.4 new drugs approved per year and in India a total of 70 new drugs were approved, with an average of 14 new drugs approved per year. There were more number of new drug approvals in antineoplastic and immunomodulating agents (L) ATC group in all the three regions (US=66; $\mathrm{EU}=61$ and India $=17$ ).

Conclusions: For new drugs approved between 2011 and 2015, India has lagged behind the US and the EU in approval of new drugs. There was no difference in the patterns of new drug approvals with respect to the therapeutic areas.
\end{abstract}

Keywords: Priority review, CDSCO, EMA, FDA, ATC group

\section{INTRODUCTION}

In most countries, the regulatory agencies authorize drugs for marketing. The main regulatory body for the Indian pharmaceutical industry is the Central Drugs Standard Control Organization (CDSCO). The Drug Controller General of India (DCGI) is the controlling body for the CDSCO. The office of the Drug Controller General of India is responsible for the approval of new drugs and clinical trials in India. In the European Union (EU), the European Medicines Agency (EMA) began operating in 1995. ${ }^{1}$ The EMA is a decentralised agency of the EU, located in London. The EMA is responsible for the scientific evaluation, supervision and safety monitoring of medicines developed by pharmaceutical companies for use in the EU. The United States (US) Food and Drug
Administration (FDA), founded in 1906, is one of the oldest federal regulatory agencies. ${ }^{2}$

There are many local and multinational pharma companies selling their drug products in India. Most of the local pharma companies are mainly in generic drug business. There is a change in the regulatory environment after a system of product patents in India since 2005. After a system of product patents, it's not possible for the Indian companies to launch patented new drugs. Indian physicians and patients mainly depend on multinational pharma companies for novel drugs.

The average number new drug approval by the Indian drug regulatory authority was 34.46 per year from 1999 through 2011 and U.S. FDA averaged about 28 new drug approvals per year from 2006 through 2014..$^{3,4}$ It's 
interesting to see the trend of new drug approvals after a system of product patents in India. Therefore, identifying the actual status of the new drug approvals in India would provide important information. The purpose of this study was to compare the new drug approvals in India with the US and the EU regions and assess the patterns of new drug approvals with respect to therapeutic areas.

\section{METHODS}

We obtained information about regulatory approval of new drugs in the US, EU, or India between 2011 and 2015 from the following publicly accessible databases:

1. The US: The Center for Drug Evaluation and Research (CDER), New Molecular Entity (NME) and New Biological Approvals, US Food and Drug Administration (FDA),

2. The EU: The European Public Assessment Report (EPAR), Committee for Medicinal Products for Human Use (CHMP), European Medicines Agency (EMA), ${ }^{6}$

3. India: The Central Drugs Standard Control Organization (CDSCO), List of approved drug. ${ }^{7}$

Information about name of approved drug, indication and date of issue of marketing approval was retrieved from the above sources. The definition of "new drug" included new molecular entities (NMEs) and new biologics. These analyses don't include generic drugs, biosimilar and supplemental approvals (e.g. additional indication, additional strength, new dosage form etc.) to new drugs. The information from the regulatory agencies online databases was entered and analysed using a Microsoft Excel worksheet (Microsoft Office 2010).

For the drug products identified the following features were recorded: International Non-proprietary Names
(INN), the ATC code as per WHO Anatomical Therapeutic Chemical (ATC) classification, single or combination product, review classification (priority review drug, standard review drug, orphan drug) and approval date. ${ }^{8}$

\section{RESULTS}

We identified 509 new drug approvals between 2011 and 2015 that were approved by one or more of the three regulatory agencies. Total 182 new drugs were approved in US during the period of 2011 to 2015, with an average of 36.4 new drugs approved per year. For the same period a total of 257 new drugs were approved in the EU, with an average of 51.4 new drugs approved per year and in India a total of 70 new drugs were approved, with an average of 14 new drugs approved per year. The year wise distribution of new drug approvals in the US, EU and India is shown in Figure 1.

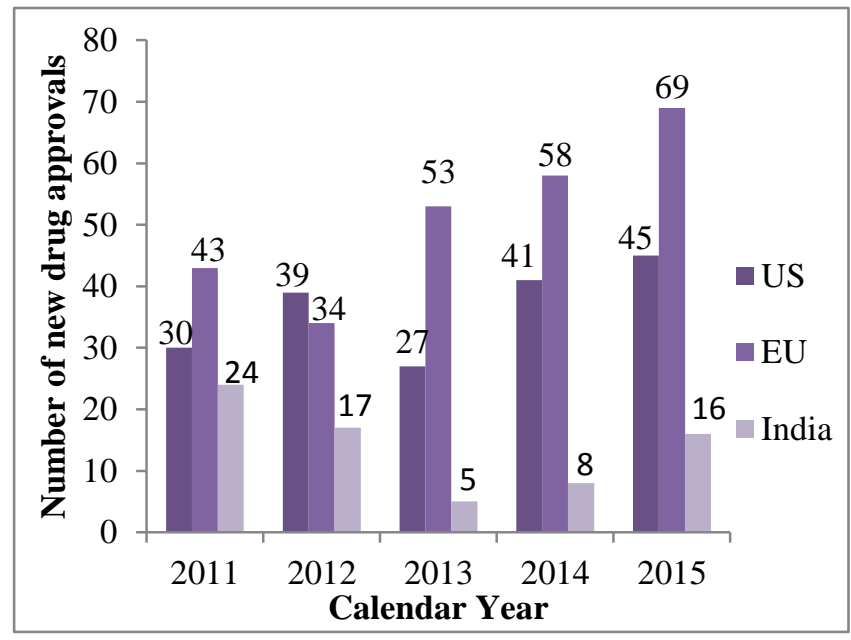

Figure 1: Number of new drug approvals per year for US, EU and India, 2011-2015.

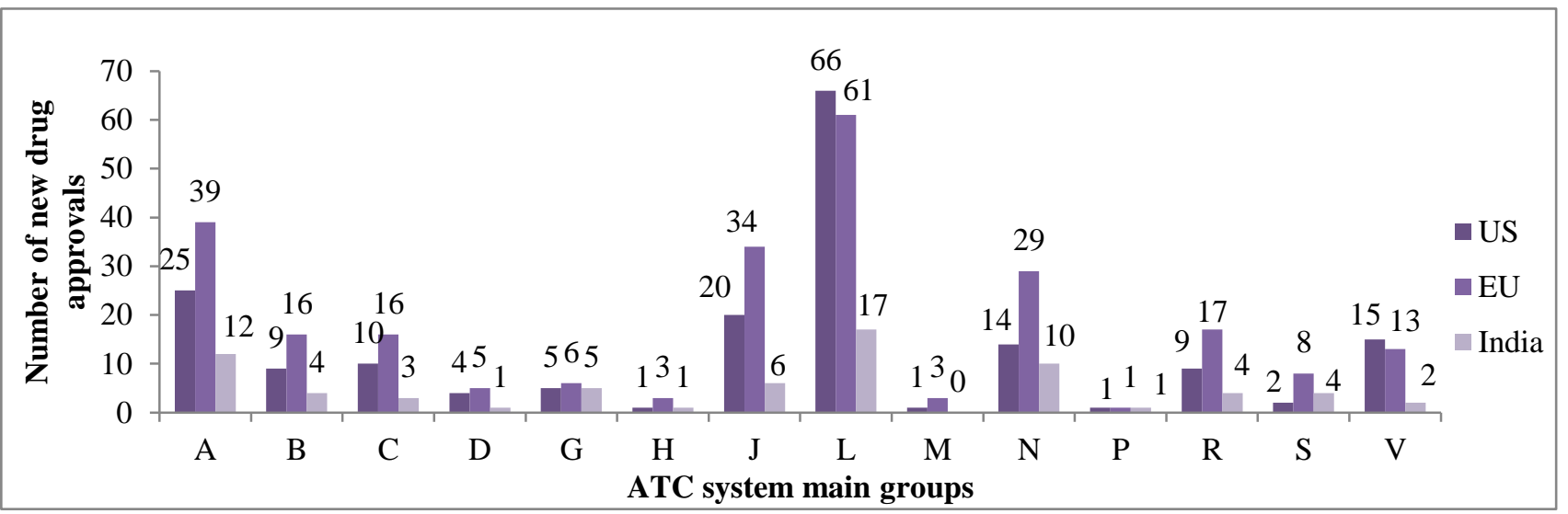

ATC Group: A (Alimentary tract and metabolism), B (Blood and blood forming organs), C (Cardiovascular system), D (Dermatologicals), G (Genito urinary system and sex hormones), H (Systemic hormonal preparations, excluding sex hormones and insulins), J (Antiinfectives for systemic use), L (Antineoplastic and immunomodulating agents), M (Musculo-skeletal system), N (Nervous system), P (Antiparasitic products, insecticides and repellents), R (Respiratory system), S (Sensory organs), V (Various).

Figure 2: Number of new drug approvals as per ATC classification in US, EU and India, 2011-2015. 
Figure 2 shows the new drug approvals for each group of ATC classification in US, EU and India. There were more number of new drug approvals in antineoplastic and immunomodulating agents (L) ATC group in all the three regions $(\mathrm{US}=66 ; \mathrm{EU}=61$ and India= 17). The total number of new drug approvals was higher in EU ( $n=$ 257), but new drug approvals for antineoplastic and immunomodulating agents (L) ATC group was higher in US (66 in US and 61 in EU). New drug approvals for alimentary tract and metabolism (A) ATC group was second highest in all the three regions $(\mathrm{US}=25 ; \mathrm{EU}=39$ and India= 12).

The information regarding orphan versus nonorphan status was not available for India. The FDA approved a larger proportion of orphan-designated new drugs than the EMA (39.44\% versus $20.23 \%$ ) (Table 1 ). The FDA approved 90 new drugs under priority review and 92 new drugs under standard review. The information with respect to priority or standard review was not available for EU and India.

Table 1: Characteristics of new drugs approved in US, EU and India from 2011 through 2015.

\begin{tabular}{|c|c|c|c|}
\hline Variable & $\begin{array}{l}\text { US } \\
(n=182)\end{array}$ & $\begin{array}{l}\text { EU } \\
(n=257)\end{array}$ & $\begin{array}{l}\text { India } \\
(n=70)\end{array}$ \\
\hline $\begin{array}{l}\text { Average approval } \\
\text { per year }\end{array}$ & 36.4 & 51.4 & 14 \\
\hline \multicolumn{4}{|l|}{ Therapeutic class } \\
\hline $\begin{array}{l}\text { Alimentary tract } \\
\text { and metabolism }\end{array}$ & 25 & 39 & 12 \\
\hline $\begin{array}{l}\text { Antiinfectives for } \\
\text { systemic use }\end{array}$ & 20 & 34 & 6 \\
\hline $\begin{array}{l}\text { Antineoplastic and } \\
\text { immunomodulating } \\
\text { agents }\end{array}$ & 66 & 61 & 17 \\
\hline Nervous system & 14 & 29 & 10 \\
\hline Respiratory system & 9 & 17 & 4 \\
\hline Other & 48 & 77 & 21 \\
\hline \multicolumn{4}{|l|}{ Orphan status\# } \\
\hline Orphan designation & $\begin{array}{l}71 \\
(39.44 \%)\end{array}$ & $\begin{array}{l}52 \\
(20.23 \%)\end{array}$ & - \\
\hline $\begin{array}{l}\text { Nonorphan } \\
\text { designation }\end{array}$ & $\begin{array}{l}111 \\
(60.56 \%)\end{array}$ & $\begin{array}{l}205 \\
(79.77 \%)\end{array}$ & - \\
\hline \multicolumn{4}{|l|}{ Review status* } \\
\hline Priority & 90 & - & - \\
\hline Standard & 92 & - & - \\
\hline
\end{tabular}

\#: Central Drugs Standard Control Organization (CDSCO) India does not designate orphan versus nonorphan status.

*: Status with respect to priority or standard review was not analyzed for EU and India because the information regarding review classification was not available from EMA and CDSCO databases.

\section{DISCUSSION}

This study shows that the number of new drug approvals in India between 2011 and 2015 is less as compared to the US and the EU. As most of the pharmaceutical and biopharmaceuticals companies are more interested in the developed markets like the US and EU for their novel drugs, there may be less regulatory submission in India for new drugs. Our previous analysis showed substantial drug lag in approval of new drugs in India compared with the United States and European Union. ${ }^{9-11}$

This study has not explored the disease burden of all three regions. However, the pattern of new drug approvals shows similar upward trends for oncology drugs in all three regions. This trend shows more commercial interest in drug development then healthcare needs of specific region. As drug development cost is very high, small local pharmaceutical and biopharmaceuticals companies cannot afford developing new drugs. As per World Trade Organisation (WTO), from the year 2005, India granted product patent recognition to all new chemical entities (NCEs). Many Indian origin pharmaceutical and biopharmaceuticals companies are taking interest in drug development now. One of the examples of novel drug developed by Indian origin pharmaceutical company is saroglitazar (Lipaglyn). Saroglitazar is the first glitazar to be approved in the world and is the first new chemical entity (NCE) discovered and developed indigenously by an Indian Pharma Company (Cadila Healthcare Ltd). ${ }^{12}$ Saroglitazar has been approved for marketing in India for treating diabetic dyslipidemia or hypertriglyceridemia in type 2 diabetes, not controlled by statins alone.

In last decade (from 2006 through 2014) U.S. FDA averaged about 28 novel drug approvals per year. ${ }^{4}$ The annual number of novel drug approvals in India is not comparable with the US and the EU regions. Regulatory processes differ widely in different countries. However, there is a need to improve the regulatory processes in India to enhance the clinical trial and new drug approvals. The Indian regulatory authority has to initiate some measures to reduce the delay in approval.

In conclusion, our analysis of new drugs approved in the US, the EU and India between 2011 and 2015 shows that India has lagged behind the US and the EU in approval of new drugs. There was no major difference in the patterns of new drug approvals with respect to therapeutic area as in all the three regions proportionately more number of drugs approved in the antineoplastic and immunomodulating agents ATC group.

\section{Funding: No funding sources \\ Conflict of interest: None declared \\ Ethical approval: Not required}




\section{REFERENCES}

1. The European Medicines Agency (EMA). Available at

www.ema.europa.eu/ema/index.jsp?curl=pages/about _us/general/general_content_000235.jsp\&mid=.

Accessed 2 January 2016.

2. U.S. Food and Drug Administration. The history of drug regulation in the United States. Available at www.fda.gov/downloads/AboutFDA/WhatWeDo/His tory/ProductRegulation/PromotingSafeandEffectiveD rugsfor100Years/UCM114468.pdf. Accessed 2 January 2016.

3. Kataria BC, Bhavsar VH, Donga BN. Contemplation on approved drugs in India from 1999 through 2011. Asian J Pharm Clin Res. 2012;5(3):25-9.

4. U.S. Food and Drug Administration. New molecular entity and new therapeutic biological product approvals for 2015. Available at www.fda.gov/downloads/Drugs/DevelopmentApprov alProcess/DrugInnovation/UCM481709.pdf. Accessed 3 January 2016.

5. U.S. Food and Drug Administration. Drug approval reports. Available at www.accessdata.fda.gov/scripts/cder/drugsatfda/inde x.cfm?fuseaction=Reports.ReportsMenu. Accessed 1 January 2016.

6. European Medicines Agency. The European Public Assessment Report. Available at www.ema.europa.eu/ema/index.jsp?curl=pages/medi cines/landing/epar_search.jsp\&jsenabled=true.

Accessed 1 January 2016.

7. The Central Drugs Standard Control Organization (CDSCO). List of approved drug. Available at www.cdsco.nic.in/forms/SearchMore. $\operatorname{aspx}$ ? Id=11. Accessed 3 January 2016.

8. WHO Collaborating Centre for Drug Statistics Methodology, ATC/DDD Index 2016. Available at www.whocc.no/atc_ddd_index/. Accessed 3 January 2016.

9. Kataria BC, Mehta DS, Chhaiya SB. Drug lag for cardiovascular drug approvals in India compared with the US and EU approvals. Indian Heart J. 2013;65(1):24-9.

10. Kataria BC, Mehta DS, Chhaiya SB. Approval of antineoplastic agents in India: comparison with the US and EU regions. Int $\mathrm{J}$ Basic Clin Pharmacol. 2012;1(1):13-21.

11. Kataria BC, Mehta DS, Mehta SJ. Drug lag for antimicrobial agents: comparison of the US, EU and India approvals. Natl J Med Res. 2012;2(3):264-8.

12. Cadila Healthcare Ltd. Lipaglyn. Available at www.lipaglyn.com/about_lipaglyn.html. Accessed 3 January 2016.

Cite this article as: Kataria $\mathrm{BC}$, Panchal $\mathrm{PJ}$, Panchasara AK, Pandya AS, Parmar MR. Comparison of new drug approval by regulatory agencies of US, EU and India. Int J Basic Clin Pharmacol 2016;5:112-5. 